\title{
The Production of Riboflavin and D-Arabitol by Debaryomyces subglobosus
}

\author{
By F. B. ANDERSON AND G. HARRIS \\ Brewing Industry Research Foundation, Nutfield, Surrey
}

(Received 24, April 1963)

\begin{abstract}
SUMMARY
Debaryomyces subglobosus (British National Collection of Yeast Cultures, NCYC 459) excretes riboflavin at the end of the growth period in batch culture and the yield depends on the concentration of iron in the medium. Yields of riboflavin in excess of $200 \mu \mathrm{g} . / \mathrm{ml}$. were obtained in media of low iron content but production was completely inhibited at $\mathrm{Fe}$ concentrations greater than $200 \mu \mathrm{g}$./1. D-Arabitol was produced simultaneously, increased yields of it being obtained at high iron concentration, but riboflavin production was then decreased. Procedures are described for the recovery of riboflavin and $\mathrm{D}$-arabitol from the culture fluid.
\end{abstract}

\section{INTRODUCTION}

Riboflavin is produced to some degree by a variety of micro-organisms (see, for example, Pridham, 1952). Outstanding in this respect are the two Ascomycetes, Eremothecium ashbyii (Guilliermond, Fontaine \& Raffy, 1935; Raffy, 1937) and Ashbya gossypii (Wickerham, Flickinger \& Johnson, 1946; Tanner, Wickerham \& Van Lanen, 1948). These fungi are capable of giving yields of riboflavin in the region of $2000 \mu \mathrm{g}$./ml. under appropriate conditions (Moss \& Klein, 1947; Pridham, 1951). Significant amounts of riboflavin are also yielded by certain clostridia (e.g. Meade, Rodgers \& Pollard, 1947) and by some yeasts including, mainly, species of the genus Candida (Burkholder, 1943; Tanner, Vojnovich \& Van Lanen, 1945) and a Torulopsis sp. (Dikanskaya, 1962). Unlike the fungal processes, production of riboflavin by clostridia and yeasts is generally subject to inhibition by iron; for example, Tanner et al. (1945) found the optimal concentration of iron for Candida guilliermondii was 5-10 $\mu \mathrm{g} . / \mathrm{l}$. and that iron concentrations of $100 \mu \mathrm{g}$. $/ 1$. sharply decreased the yield of riboflavin. With this yeast Enari \& Kauppinen (1961) showed that the inhibition of riboflavin production by iron could be annulled to some extent by adding cobalt to the medium.

Since the first observation of the production of $D$-arabitol by members of the genus Zygosaccharomyces (Spencer \& Sallans, 1956) it has been reported that other yeasts give rise to this and related substances (e.g. Onishi, 1960). Fermentation procedures have been worked out for the production of $\mathbf{D}$-arabitol and yields of as much as $45 \%$ by weight based on the sugar content of the medium have been obtained (Lavin \& Holloway, 1960).

The present paper describes the conditions for producing riboflavin and D-arabitol by the yeast Debaryomyces subglobosus. 


\section{METHODS}

Organism. A strain of Debaryomyces subglobosus (NCYC 459) was used except where otherwise indicated. It was maintained on a medium containing (g./l.): malt extract, 3; yeast extract, 3; peptone, 5; glucose, 10; agar, 20 (Wickerham, 1951).

Culture media. The defined medium used for the production or riboflavin and $\mathrm{D}$ arabitol contained salts and vitamins as formulated by Wickerham (1951). Trace elements were added as $\mathrm{H}_{3} \mathrm{BO}_{3}, \mathrm{MnSO}_{4} \cdot \mathrm{H}_{2} \mathrm{O}, \mathrm{CuSO}_{4} \cdot \mathbf{5} \mathrm{H}_{2} \mathrm{O}, \mathrm{Na}_{\mathbf{2}} \mathrm{MoO}_{4} \cdot \mathbf{2} \mathrm{H}_{2} \mathrm{O}$, $\mathrm{ZnSO}_{4} \cdot 7 \mathrm{H}_{2} \mathrm{O}$ and $\mathrm{KI}$ to give final concentrations of boron, manganese, copper and molybdenum (20 $\mu \mathrm{g}$. each/l.), zinc (140 $\mu \mathrm{g} . / 1$.) and potassium iodide (100 $\mu \mathrm{g} . / 1$.$) .$ Glucose in various concentrations and ammonium sulphate $(0.5 \%, \mathrm{w} / \mathrm{v})$, except where otherwise stated, provided the sole sources of carbon and nitrogen, respectively. Iron was added as $\mathrm{FeCl}_{3} \cdot 6 \mathrm{H}_{2} \mathrm{O}$ and cobalt as $\mathrm{CoCl}_{2} \cdot 6 \mathrm{H}_{2} \mathrm{O}$.

Solutions of glucose, of ammonium sulphate + salts, and of trace elements were autoclaved at $120^{\circ}$ for $15 \mathrm{~min}$. Solutions of the vitamins were sterilized by Seitz filtration.

The cultures, contained in Roux bottles or medical bottles, plugged with cotton wool, were shaken at $25^{\circ}$.

Riboflavin assay. The riboflavin excreted into the medium was estimated by optical density measurements of cell-free broth at 375 and $445 \mathrm{~m} \mu$ and a calibration curve prepared by using pure riboflavin.

Chromatography: qualitative. Descending paper chromatograms were prepared at room temperature on Whatman No. 1 paper with the following solvents: $(A)$ butanol + acetic acid + water $(4+1+1$, by vol.; Hais \& Pecàkovà, 1949); $(B)$ propanol + ethyl acetate + water $(7+1+2$, by vol.; Gross \& Albon, 1953); $(C)$ methylethylketone + acetic acid + water $(9+1+1$, by vol.; saturated with boric acid; Rees \& Reynolds, 1958).

Silver nitrate + sodium hydroxide (Trevelyan, Proctor \& Harrison, 1950), or periodate + benzidine (Cifonelli \& Smith, 1954), was used as the spray reagent.

Chromatography: preparative. The preparative separation of $\mathrm{D}$-arabitol from glucose was achieved by descending chromatography at room temperature on Whatman No. 3 paper with solvent $B$ above. The separated components were eluted from the paper with water.

Removal and estimation of iron. Glucose was freed from iron by the passage of an aqueous solution of the sugar $(6 \%, \mathrm{w} / \mathrm{v})$ through a column containing excess Zeokarb 225 cation-exchange resin which had been converted to the $\mathrm{H}^{+}$form by treatment with $2 \mathrm{~N}-\mathrm{HCl}$ followed by the removal of the excess acid by washing with distilled water. The glucose concentration of the eluate was determined polarimetrically. Whole medium, less trace elements and vitamins, was in certain cases freed from iron by treatment with 8 -hydroxyquinoline ( $2 \%$ in chloroform) as is described in Results. Iron was estimated in concentrated medium by the $o$-phenanthroline method (Bandemer \& Schaible, 1944).

Recovery of riboflavin and $\mathrm{D}$-arabitol from the culture fluids. All evaporations were carried out at $20^{\circ}$ under reduced pressure.

The culture fluid, after removal of the organism by centrifugation, was evaporated to small volume and ethanol added to $70 \%(\mathrm{v} / \mathrm{v})$. After removal of the resultant precipitate, the solution was evaporated to small volume and passed on to a column 
of Dowex 50 cation-exchange resin $\left(\mathrm{H}^{+}\right.$form); the riboflavin was retained at the top. Neutral and acidic materials were first eluted from the column with water anp the riboflavin was then eluted with dilute ammonium hydroxide solution. The ammoniacal solution was evaporated to dryness and the resultant yellow residue was crystallized and recrystallized from dilute acetic acid to give a product which proved identical with an authentic sample of riboflavin.

The aqueous eluate from the Dowex 50 column was evaporated to small volume and the solution was then passed on a column of Dowex 1 anion-exchange resin previously converted to the acetate form by successive treatment with $2 \mathrm{~N}-\mathrm{NaOH}$, water and $2 \mathrm{M}$-sodium acetate and finally washing with water until neutral. The neutral components of the culture fluid were eluted from the column with water and this eluate evaporated to dryness. In those cases when the bulk of the glucose had been utilized by the yeast, the $\mathrm{D}$-arabitol was readily obtained in pure form from the residue by crystallization and recrystallization from ethanol. Where there was an appreciable amount of glucose remaining at the end of the growth, this was first separated from the $\mathbf{D}$-arabitol by chromatography.

\section{RESULTS}

It was found that cotton wool plugs in the culture vessels allowed access of sufficient air for the production of riboflavin; more vigorous aeration did not increase the yields. The media were unbuffered and with ammonium sulphate as $\mathrm{N}$-source the $\mathrm{pH}$ value decreased from $5 \cdot 2$ (initial) to about $2 \cdot 6$ within $24 \mathrm{hr}$. after inoculation. The maximum yields of the products were, in the main, produced 5-6 days after inoculation.

\section{Production of riboflavin}

Untreated medium. Defined medium (400 ml.) containing glucose $(1 \%, \mathrm{w} / \mathrm{v})$ was inoculated with $0.1 \mathrm{ml}$. of a $48 \mathrm{hr}$. culture of the organism grown in the same medium. At the end of the logarithmic period of growth (after incubation for about $26 \mathrm{hr}$.), the appearance of yellow pigment in the medium was observed. The absorption spectrum of samples of cell-free culture fluid was identical with that of a dilute solution of authentic riboflavin in defined medium. The identity of the pigment was confirmed by chromatographic analysis in solvent $A$; a single fluorescent spot with the same mobility $\left(R_{f} \mathbf{0 \cdot 3 0}\right)$ as that of riboflavin was obtained. Riboflavin production was followed by determiming the extinction at 375 and $445 \mathrm{~m} \mu$ of samples of cell-free culture fluid withdrawn at intervals from the cultures. A maximum yield of more than $60 \mu \mathrm{g}$. riboflavin/ml. was obtained (Fig. 1).

When defined medium containing glucose $(4 \%, \mathrm{w} / \mathrm{v})$ was similarly inoculated, a much lower yield of riboflavin resulted (about $20 \mu \mathrm{g} . / \mathrm{ml}$.; Fig. 1). There was no significant difference in the amount of growth at the two glucose concentrations used.

The effect of iron. To examine the possibility that the lower yield of riboflavin produced at the higher glucose concentration $(4 \%, \mathrm{w} / \mathrm{v})$ was due to the introduction of an increased concentration of iron with the sugar, the following media were inoculated with the organism: $(a)$ defined medium containing glucose $(4 \%, \mathrm{w} / \mathrm{v}$, untreated); $(b)$ defined medium containing glucose $(4 \%, \mathrm{w} / \mathrm{v})$ which had been treated previously with Zeokarb 225 cation-exchange resin $\left(\mathrm{H}^{+}\right.$form) to remove 
cations. The production of riboflavin in medium $(a)$ was similar to that observed above with untreated glucose $(4 \%, w / v$; maximum yield of about $20 \mu \mathrm{g}$. riboflavin $/ \mathrm{ml}$.), while in medium (b) a maximum yield of $120 \mu \mathrm{g}$. riboflavin/ml. was obtained (Fig. 1).

An increase in the ammonium sulphate concentration from 0.5 to $1.5 \%(w / v)$ in medium containing untreated glucose $(1 \%, w / v)$ decreased the yield of riboflavin from 60 to $25 \mu \mathrm{g} . / \mathrm{ml}$. This again could be accounted for by the increased iron concentration.

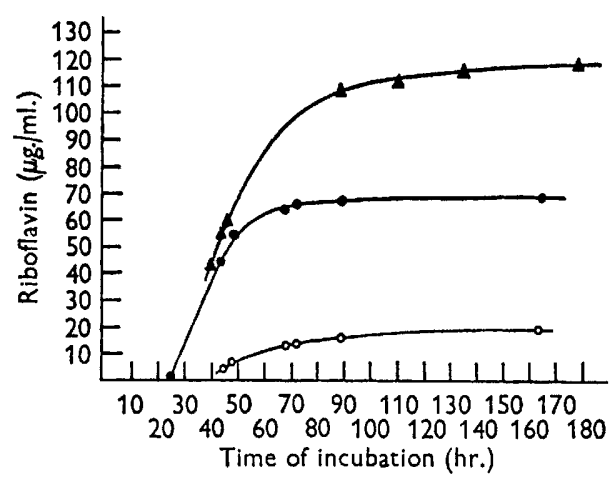

Fig. 1

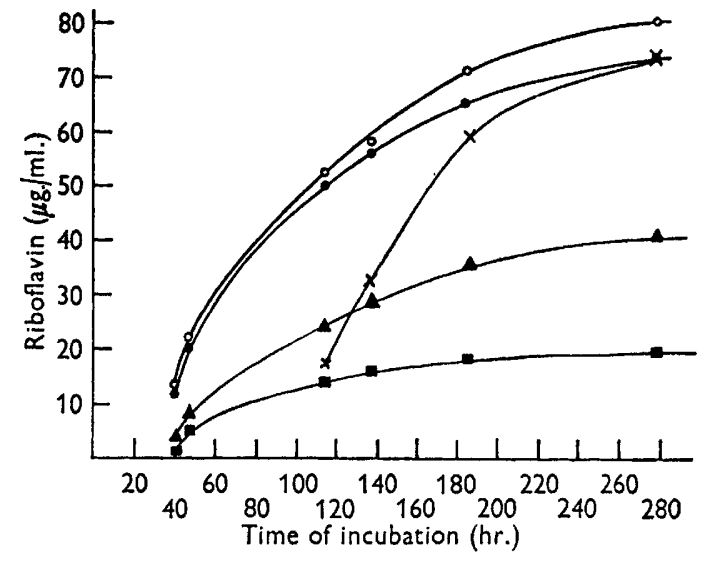

Fig. 2

Fig. 1. Production of riboflavin by Debaryomyces subglobosus (NCYC 459) in defined medium containing untreated and treated (de-ferrated) glucose. -, $1 \%$ untreated glucose; $O-O, 4 \%$ untreated glucose; $\Delta-\Delta, 4 \%$ glucose treated with Zeokarb 225 cation-exchange resin.

Fig. 2. Effect of iron and cobalt on the production of riboflavin by Debaryomyces subglobosus (NCYC 459). The metals were added at the following concentrations to defined medium containing resin-treated glucose $(4 \%, w / v)$ and the production of riboflavin was determined. - , No addition; $\bigcirc-O$, iron $20 \mu \mathrm{g} . / 1$; $\Delta-\Delta$, iron $40 \mu \mathrm{g} . / 1$;

口- , iron $80 \mu \mathrm{g} . / 1 . ; \times-x$, iron $80 \mu \mathrm{g} . / \mathrm{l}$., cobalt $20 \mathrm{mg} . / 1$.

To establish that it was removal of iron and not some other material from the glucose by the resin which resulted in the observed increase in riboflavin production and at the same time to investigate the effect of cobalt on the inhibition of riboflavin production by iron, the following media were inoculated with the organism: defined medium containing $4 \%(\mathrm{w} / \mathrm{v})$ glucose (previously treated with resin) and added iron to give final concentrations of $0,20,40$ and $80 \mu \mathrm{g} . \mathrm{Fe} / \mathrm{l}$, and this last medium + cobalt (20 mg./1.). The course of the production of riboflavin was followed (Fig. 2). In this particular series, the maximum yields of riboflavin were not attained until after a prolonged period of incubation. Iron had a marked inhibitory effect on riboflavin production and the inhibition was decreased by adding cobalt. The presence of cobalt prolonged the lag phase before growth and consequently delayed riboflavin production.

Optimal concentration of iron. The iron concentration of the defined medium which contained untreated glucose $(4 \%, \mathrm{w} / \mathrm{v})$ was estimated by the 0 -phenanthroline method to be about $100 \mu \mathrm{g}$. Fe/l. The medium less trace elements and vitamins was extracted $(\times 4)$ with equal volumes of a solution of 8 -hydroxyquinoline $(2 \%$ in 
chloroform) and then with chloroform $(\times 3)$. Traces of chloroform were removed by passing air through the medium. Little or no iron was detected in concentrates of this treated medium. Trace elements, vitamins and iron at various concentrations, were added to samples $(100 \mathrm{ml}$.) of treated medium which were then inoculated with organism and incubated. Riboflavin production was determined (Table 1). The optimal concentration of iron for riboflavin production was in the range 10 to $20 \mu \mathrm{g}$./l. Production of riboflavin was not greatly decreased at concentrations up to $80 \mu \mathrm{g} . \mathrm{Fe} / \mathrm{l}$. (about $30 \%$ inhibition) but there was complete inhibition at $200 \mu \mathrm{g}$. $\mathrm{Fe} / \mathrm{l}$, and above.

Table 1. Optimal concentration of iron for the production of riboflavin by Debaryomyces subglobosus (NCYC 459)

The organism was grown at $25^{\circ}$ in defined medium containing glucose $(4 \%, \mathrm{w} / \mathrm{v})$ and iron at the given concentrations. Riboflavin production was estimated after 7 days.

$\begin{array}{cc}\begin{array}{c}\text { Iron } \\ (\mu \mathrm{g} \cdot / \mathrm{l} .)\end{array} & \begin{array}{c}\text { Yield of } \\ \text { riboflavin } \\ (\mu \mathrm{g} \cdot / \mathrm{ml} .)\end{array} \\ 0 & 60 \\ 5 & 63 \\ 10 & 90 \\ 20 & 95 \\ 40 & 85 \\ 80 & 64 \\ 100 & 56 \\ 200 & 0\end{array}$

The effect on riboflavin production of nitrogen sources other than ammonium sulphate

Corn steep liquor. Corn steep liquor (CSL; kindly supplied by Corn Products Ltd., containing sugars, $2 \cdot 3 \%$; nitrogen, $3.9 \%$; iron, 156 p.p.m.) was diluted $1 / 4$ with distilled water. Iron was removed from a portion of this solution by the treatment with 8-hydroxyquinoline, described above. Media were prepared containing $4 \%(\mathrm{w} / \mathrm{v})$ glucose (previously treated with resin), salts, trace elements, vitamins + one of the following $\mathrm{N}$-sources: (i) ammonium sulphate $(0.5 \%, \mathrm{w} / \mathrm{v})$; (ii) untreated CSL (1/10 dilution); (iii) 8-hydroxyquinoline-treated CSL (1/10 dilution). The media containing CSL were thus of nitrogen contents comparable with the medium containing $0.5 \%$ ammonium sulphate. Riboflavin production was determined in these media. Uninoculated medium containing CSL showed appreciable absorption in the range $320-500 \mathrm{~m} \mu$ and corrections for this were necessary in the estimation of riboflavin formed in these media. As compared with a yield of riboflavin $90 \mu \mathrm{g} . /$ ml. in medium (i) in 7 days, no riboflavin was produced in medium (ii) and only $56 \mu \mathrm{g} . / \mathrm{ml}$. in medium (iii). CSL therefore presented no advantage in riboflavin production though all the media supported heavy growth.

Amino acids, purines, and pyrimidines. To samples of defined medium (10 ml.) containing resin-treated glucose $(4 \%, \mathrm{w} / \mathrm{v})$ the following L-amino acids, purines and pyrimidines were separately added to $0.005 \mathrm{~m}: \alpha$-alanine, arginine, asparagine, aspartic acid, cysteine, cystine, glutamic acid, glycine, leucine, lysine, methionine, proline, threonine, valine, adenine, guanine, thymine, uracil, xanthine. The media were inoculated and incubated in the normal way. A significant increase in the production of riboflavin was obtained in the presence, singly, of alanine, arginine, 
asparagine, glycine, threonine, valine, adenine, guanine, xanthine, namely, 170$200 \mu \mathrm{g}$. riboflavin $/ \mathrm{ml}$. as compared with $140 \mu \mathrm{g} . / \mathrm{ml}$. in controls with no supplementary $\mathrm{N}$-source. Cystine and uracil decreased the yield, giving only 86 and $100 \mu \mathrm{g}$. riboflavin/ml., respectively. All the $\mathrm{N}$-supplemented media gave an increase in the growth of the organism: 1.4-1.9 mg. dry wt./ml. as compared with 1.2 mg. dry wt./ml. in the controls, with the exception of the cysteine-supplemented medium which gave no growth and no riboflavin.

Glycine. Since glycine promoted riboflavin production, defined medium (400 ml.), containing resin-treated glucose $(4 \%, w / v)$, but with glycine $(0.5 \%, w / v)$ in place of ammonium sulphate, was inoculated with the organism. Maximum yields of riboflavin of the order of $200-240 \mu \mathrm{g} . / \mathrm{ml}$. were obtained. The $\mathrm{pH}$ value of the medium did not follow the same course as when ammonium sulphate was the $\mathrm{N}$ source. In the glycine medium, after an initial decrease to $\mathrm{pH} 4 \cdot 4$ (at about $20 \mathrm{hr}$.), there was a gradual increase to about $\mathrm{pH} 8$ at about $120 \mathrm{hr}$; the maximum yield of organism was equivalent to $1.8 \mathrm{mg}$. dry wt./ml.

Riboflavin production by Saccharomyces rouxii. A strain of Saccharomyces rouxii (NCYC 561) was grown in the defined medium $(100 \mathrm{ml}$.) containing resin-treated glucose $(4 \%, \mathrm{w} / \mathrm{v})$ and ammonium sulphate $(0.5 \%, \mathrm{w} / \mathrm{v})$. Yields of riboflavin of the order of 5-6 $\mu \mathrm{g}$. $/ \mathrm{ml}$. were obtained after incubation for 5 days.

\section{Recovery of riboflavin from cultures}

The supernatant liquid ( $400 \mathrm{ml}$.), after removal of organism by centrifugation of a grown culture (riboflavin content $60 \mu \mathrm{g} . / \mathrm{ml}$.), was processed as described in Methods. A column $(10 \times 2 \mathrm{~cm}$. diameter $)$ containing Dowex 50 resin $\left(\mathbf{H}^{+}\right.$form $)$was used. The final product (14 mg., crystallized from dilute acetic acid and dried) had m.p. and

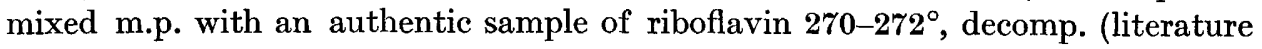
gives riboflavin $\left.271^{\circ}\right)$. A solution of the product in water $(40 \mu \mathrm{g} . / \mathrm{ml}$.) gave an absorption spectrum identical with that of an aqueous solution of authentic riboflavin (maximum at 220, 268, 375 and $445 \mathrm{~m} \mu$ ). The infra-red spectrum of the product (KBr disk) was identical with that of an authentic sample of riboflavin.

\section{Production of D-arabitol}

Identification of $\mathrm{D}$-arabitol in culture fluid. After removal of organism by centrifugation from a culture in defined medium containing resin-treated glucose $(4 \%$, $\mathrm{w} / \mathrm{v}$ ), the supernatant fluid (riboflavin content $100 \mu \mathrm{g} . / \mathrm{ml}$.) was processed as described in Methods successively with cation- and anion-exchange resins. Chromatographic analysis with propanol + ethyl acetate + water solvent $(B)$ of samples of the aqueous eluate from the Dowex 1 resin showed a major component $\left(\boldsymbol{R}_{f}, \mathbf{0 \cdot 4 3}\right)$ in addition to glucose $\left(\boldsymbol{R}_{f}, \mathbf{0 . 3 3}\right)$ and trace components $\left(\boldsymbol{R}_{f}, 0.51,0.64,0.74\right)$ with the silver nitrate $+\mathrm{NaOH}$ spray reagent (i). The development of the spot produced by this component was slower than that of reducing sugars. No positive reducing reaction was obtained with the aniline oxalate spray reagent (Horrocks \& Manning, 1949). The periodate + benzidine spray reagent (ii) and the bromocresol purple + boric acid reagent of Bradfield \& Flood (1950) yielded positive results. These findings suggested that the material was a sugar alcohol. A concentrate of the mixture was run on Whatman No. 3 paper in solvent $(B)$ and the strip corresponding to $R_{f} \mathbf{0 \cdot 4 3}$ 
was extracted with water. Chromatography of a sample of the resultant solution gave a single spot $\left(R_{f}, 0 \cdot 43\right.$, with solvent $(B)$, spray reagents (i) and (ii)). The remainder of the solution was evaporated to dryness and the solid residue was crystallized from hot ethanol $(\times 3)$. The dry product had m.p. $100^{\circ}$ and a chromatographic mobility $\boldsymbol{R}_{f} \mathbf{0 \cdot 4 3}$ in solvent $(B)$. Its chromatographic mobility in methylethylketone + acetic acid + water solvent $(C)$ was consistent with the substance being either D-arabitol or ribitol $\left(\boldsymbol{R}_{f}, \mathbf{0} \cdot \mathbf{3 0}\right.$ for both; glucose, $\left.\boldsymbol{R}_{f} \mathbf{0 . 0 8}\right)$. The m.p. of a mixture with authentic $\mathrm{D}$-arabitol was $100^{\circ}$ whereas that of a mixture with ribitol (m.p. $100^{\circ}$ ) was $85^{\circ}$. The infra-red spectrum of the material was identical with that of $\mathrm{D}$-arabitol and differed slightly from that of ribitol. The identity of the product as D-arabitol was thus established.

The course of the production of D-arabitol in iron-deficient medium $(4 \%, w / v$, glucose) was followed by chromatographic analysis of samples withdrawn from the culture at intervals using solvent $(C)$, spray reagent (ii). Arabitol was not detected until about $40 \mathrm{hr}$. after inoculation, and its amount increased, together with riboflavin, over about 5 days. When the amounts of both products had reached a maximum, a considerable amount of glucose remained unchanged.

Production of D-arabitol at high iron concentration. The defined medium (400 ml.) containing glucose $(4 \%, \mathrm{w} / \mathrm{v})$ and iron (1 mg./l.) was inoculated and incubated. D-Arabitol was detected after about $40 \mathrm{hr}$; ; after 5 days no glucose remained and no riboflavin had been produced. At this time the culture fluid ( $300 \mathrm{ml}$.) after removal of organism was processed as described in Methods. The aqueous eluate from the Dowex 1 column $(20 \times 2 \mathrm{~cm}$. diameter $)$ was evaporated to dryness and the residue crystallized from ethanol. Recrystallization from ethanol $(\times 2)$ yielded a dry product ( $1 \cdot 6 \mathrm{~g}$.) identical with authentic $\mathrm{D}$-arabitol. Increasing the concentration of glucose in the medium to $10 \%(\mathrm{w} / \mathrm{v})$ did not result in an increased yield of D-arabitol.

\section{DISCUSSION}

Production of riboflavin. Inhibition by iron. In the present work the production of riboflavin by a strain of Debaryomyces subglobosus was found to be subject to inhibition by iron, the optimum concentration (10-20 $\mu \mathrm{g}$. Fe/1.) for riboflavin production being comparable with that found by Tanner et al. (1945) for Candida guilliermondii. When cobalt was included in a medium containing iron at a concentration which otherwise decreased riboflavin production, the yield of riboflavin was equivalent to that obtained at a lower iron concentration in the absence of cobalt. The cobalt thus appears to compete with iron as suggested by Enari \& Kauppinen (1961) in the case of $C$. guilliermondii.

Sources of nitrogen. Several L-amino acids, purines and pyrimidines added singly to the medium as supplementary $\mathrm{N}$-sources did not specifically stimulate riboflavin production. Goodwin \& Pendlington (1954), in a similar study on Eremothecium ashbyii, found that several similar $\mathbf{N}$-sources stimulated riboflavin production specifically while others also stimulated growth. In the case of the yeast, however, there is the added complication of the inhibition by iron and the results may be better compared with those of Goodwin \& McEvoy (1957) who investigated the effect of different $\mathrm{N}$-sources on the iron-sensitive production of riboflavin by Candida flareri. These investigators found that replacing ammonium sulphate, 
present at a lower level than is used in the present study, either completely or in part by various amino acids, greatly decreased the production of riboflavin.

Glycine was a better $\mathbf{N}$-source for riboflavin production by Debaryomyces subglobosus than was ammonium sulphate. Goodwin \& McEvoy (1959) showed that glycine as sole $\mathrm{N}$-source, at a concentration comparable with that used here, stimulated riboflavin production by Candida flareri. In the present case, however, a comparison between ammonium sulphate and glycine is complicated by the different $\mathrm{pH}$ values attained in the medium with the two compounds.

Recovery of riboflavin from the medium. Most of the methods described for the recovery of riboflavin from culture fluids depend on its precipitation in a reduced form. The procedure described here is based on the finding that riboflavin is retained on Dowex 50 resin, the retention apparently resulting from some molecular adsorption rather than from a normal cationic-exchange process since elution cannot be effected by means of dilute mineral acid but is readily achieved by dilute ammonia. It is noteworthy that Zeokarb 225 cation-exchange resin $\left(\mathbf{H}^{+}\right.$form) does not retain riboflavin. Since it is known that riboflavin is degraded under alkaline conditions, the ammoniacal solutions were not exposed to direct sunlight and the ammonia was removed as rapidly as possible.

Production of D-arabitol. The present investigation demonstrates that $\mathrm{D}$-arabitol is produced simultaneously with riboflavin by Debaryomyces subglobosus in irondeficient medium. In media of iron content such that the production of riboflavin is completely inhibited, pure $\mathrm{D}$-arabitol amounting to some $13 \%$ of the original glucose present is recovered from the medium by the procedure described.

These findings suggest a possible link between the metabolic pathways involved in the formation of riboflavin and $\mathrm{D}$-arabitol. It has been concluded from studies on the biogenesis of D-arabitol by yeasts (Spencer, Neish, Blackwood \& Sallans, 1956; Weimberg, 1962) that the phosphogluconate pathway was involved with transketolase reactions playing an additional role. Weimberg considered that the function of $\mathrm{D}$-arabitol formation may possibly be to regenerate the NADP reduced by the oxidation of glucose-6-phosphate to D-ribulose-5-phosphate. Although it was demonstrated by Weimberg (1962) that the dehydrogenase system in Saccharomyces mellis which controls the reaction,

$$
\text { D-ribose } \stackrel{\mathrm{NADPH}}{\rightleftharpoons} \text { D-arabitol, }
$$

had no metal requirements. Onishi \& Saito (1962) found that a similar NADdependent system from Pichia miso was irreversibly denatured in the absence of iron. The situation for Debaryomyces subglobosus is not known but if the formation of $\mathrm{D}$-arabitol here is at least in part via a mechanism similar to that put forward by Weimberg, then it may be postulated that the lack of iron results in some inhibition of the dehydrogenase system, by analogy with the findings of Onishi \& Saito (1962). The organism may then be considered as synthesizing riboflavin as an alternative hydrogen transport system for the regeneration of NAD or NADP. However, the lack of iron may result in an inhibition of an earlier step in the glucose monophosphate pathway. Thus, Koepsell (1950) found that with Pseudomonas fluorescens, when iron was at a low concentration, the oxidation of oxo-gluconate was very slow. It is perhaps significant that in this case a yellow pigment was excreted into the medium at low iron concentration and that the amount of iron necessary for the 
stimulation of oxidation of oxo-gluconate was in the range 100-1000 $\mu \mathrm{g}$./1. which is comparable with the concentrations which bring about the inhibition of riboflavin production by the yeast.

If riboflavin production by Debaryomyces subglobosus results from such inhibition then it may be expected that the supply of pentose material for the ribityl side-chain would be restricted to pathways other than that involving oxidation of hexose through oxo-gluconate. A study similar to that of Plaut \& Broberg (1956) using a yeast under conditions of iron-deficiency in place of the iron-independent Ashbya gossypii may show the different pattern herein suggested for the relative contributions of the pathways involved in the formation of the ribityl side-chain.

It would be expected that other micro-organisms which produce D-arabitol by the phosphogluconate pathway might be induced to produce riboflavin or some such compound in iron-deficient medium. Some support for this is found in the literature, as, for example, Onishi (1960) reported the presence of small amounts of riboflavin in culture fluids of Pichia miso (iron content of the medium unstated). Moreover it has been shown in the present study that Saccharomyces rouxii (NCYc 561), an osmophilic yeast noted for its arabitol production, does produce riboflavin when the growth medium is deficient in iron.

The authors are grateful to Dr A. H. Cook, F.R.S., for helpful discussion and encouragement during the work.

\section{REFERENCES}

Bandemer, S. L. \& Schaible, P. J. (1944). Determination of iron. Study of the ophenanthroline method. Industr. Engng Chem. (Anal.), 16, 317.

Bradfield, A. E. \& Flood, A. E. (1950). Soluble carbohydrates of fruit plants. Nature, Lond. 166, 264.

Burkholder, P. R. (1943). Synthesis of riboflavin by a yeast. Proc. nat. Acad. Sci., Wash. 29, 166.

Cifonelli, J. A. \& Sirith, F. (1954). Detection of glycosides and other carbohydrate compounds on paper chromatograms. Analyt. Chem. 26, 1132.

Dikanskaya, E. M. (1962). Increased biosynthesis of riboflavin by a yeast. Mikrobiologiya. 31, 35.

Enari, T.-M. \& KaUPpinen, V. (1961). Interaction of cobalt and iron in the riboflavin production by Candida guilliermondii. Acta chem. scand. 15, 1513.

Goodwin, T. W. \& Pendlington, S. (1954). Nitrogen metabolism in Eremothecium ashbyii. Biochem. J. 57, 631.

Goodwin, T. W. \& McEvoy, D. (1957). Riboflavin biosynthesis in Candida flareri. Biochem. J. 67, $16 \mathrm{P}$.

Goodwin, T. W. \& McEvoy, D. (1959). General factors controlling flavinogenesis in the yeast Candida flareri. Biochem. J. 71, 742.

Gross, D. \& Albon, N. (1953). Large scale chromatographic separation of sucroseraffinose mixtures on powdered cellulose for the determination of raffinose in raw sugars. Analyst, 78, 191.

Guillitermond, A., Fontaine, M. \& RafFy, A. (1935). Sur l'existence dans Eremothecium ashbyii d'un pigment jaune se rapportant au groupe des flavines. C.R. Acad. Sci., Paris, 201, 1077.

Hais, I. M. \& Pecìnovì, L. (1949). Paper chromatography of riboflavin decomposition products. Nature, Lond. 163, 768.

Horrocks, R. H. \& Manning, G. B. (1949). Partition chromatography on paper. Identification of reducing substances in urine. Lancet, 256, 1042. 
Koepseld, H. J. (1950). Gluconate oxidation by Pseudomonas fluorescens. J. biol. Chem. 186, 743.

Lavin, O. \& Holloway, J. W. (1960). Fermentation process for the production of Darabitol. U.S. Patent 2,934,474.

Meade, R. E., Rodgers, N. E. \& Pollard, H. L. (1947). Methods of preparing ribofiavin from lacteal material. U.S. Patent 2,433,232.

Moss, A. R. \& KLein, R. (1947). Improvements in or relating to the manufacture of riboflavin. British Patent 615,847.

Onishi, H. (1960). Polyalcohol production by various genera and species of yeasts. Bull. agric. chem. Soc. Japan, 24, 131.

Onishi, H. \& SaIto, N. (1962). Partial purification of polyol dehydrogenase from Pichia miso and the properties of this enzyme. Agric. biol. Chem. Japan, 26, 245.

Plaut, G. W. E. \& Broberg, P. L. (1956). Biosynthesis of riboflavin. III. Incorporation of $\mathrm{C}^{14}$-labelled compounds into the ribityl side chain. J. biol. Chem. 219, 131.

Pridham, T. G. (1951). Biological production of riboflavin. U.S. Patent 2,578,738.

Pridham, 'T. G. (1952). Microbial synthesis of riboflavin. Econ. Bot. 6, 185.

RAFFy, A. (1937). Propriétés vitaminique de la flavine de Eremothecium ashbyii. C.R.Soc. Biol., Paris, 126, 875.

Rees, W. R. \& Reynolds, T. (1958). A solvent for the paper chromatographic separation of glucose and sorbitol. Nature, Lond. 181, 767.

Spencer, J. F. T. \& Sallans, H. R. (1956). Production of polyhydric alcohols by osmophilic yeasts. Canad. J. Microbiol. $2,72$.

Spencer, J. F. T., Neish, A. C., Blackwood, A. C. \& Sallans, H. R. (1956). Polyhydric alcohol production by osmophilic yeasts: studies with $\mathrm{C}^{14}$-labelled glucose. Canad. J. Biochem. Physiol. 34, 495.

Tanner, F. W., Vojnovich, C. \& van Lanen, J. M. (1945). Riboflavin production by Candida species. Science, 101, 180.

Tanner, F. W., Wickerham, L. J. \& van Lanen, J. M. (1948). Biological process for the production of riboflavin. U.S. Patent $2,445,128$.

Trevelyan, W. E., Proctor, D. P. \& Harrison, J. F. (1950). Detection of sugars on paper chromatograms. Nature, Lond. 166, 444 .

Weimberg, R. (1962). Mode of formation of D-arabitol by Saccharomyces mellis. Biochem. biophys. Res. Comm. 8, 442.

Wickerham, L. J., Flickinger, M. H. \& Johnson, R. M. (1946). The production of riboflavin by Ashbya gossypii. Arch. Biochem. 9, 95.

Wickerham, L. J. (1951). Taxonomy of yeasts. Tech. Bull. U.S. Dep. Agric. no. 1029. 